\title{
La importancia de creer y el valor de las creencias
}

\author{
Amalio Blanco, \\ Universidad Autónoma de Madrid
}

\author{
¿Tu verdad? No, la Verdad, \\ y ven conmigo a buscarla. \\ La tuya, guárdatela \\ (Antonio Machado).
}

La conversación discurre entre Primo Levi y Ferdinando Camon. El primero es un superviviente de Auschwitz'; el segundo, un reputado periodista italiano. Levi habla en voz baja, comenta Camon, sin sobresaltos, ni arrebatos, por lo tanto, sin rencor. El final del diálogo es demoledor:

Levi: Tuve una controversia con un creyente, un amigo de Padua, de su ciudad...

Camon: ¿Usted no es creyente?

Levi: No; nunca lo he sido, quisiera serlo, pero no lo logro.

Camon: ¿Entonces, qué es su judaísmo?

Levi: Un hecho puramente cultural. De no haber existido las leyes raciales y el campo de concentración, probablemente ya no sería judío, excepto por mi apellido. Pero esta doble experiencia me ha marcado como se estampa una plancha de hierro; ya soy judío: me han cosido la estrella de David y no sólo en la ropa.

Camon: ¿Con quién tuvo esa controversia?

1. Su experiencia en aquel infierno quedo reflejada en una trilogía exquisita y estremecedora: Si esto es un hombre, Los hundidos y los salvados y La tregus. Todos ellos publicados en Muchnik Editores. 
Levi: Si recuerda El sistema periódico allí aparece "el auxiliar" en el cuento titulado "Potasio". Él es creyente, pero no es católico; vino a verme después de mi cautiverio para decirme que estaba claro que yo era un predestinado, porque había sido elegido para sobrevivir y escribir Si esto es un hombre. Debo confesarle que aquello me pareció una blasfemia, porque implicaba que Dios habría concedido ciertos privilegios salvando a algunos para condenar a otros. Debo decir que la experiencia de Auschwitz me afectó tanto que destruyó todo resto de la educación religiosa que recibí.

Camon: Es decir, Auschwitz es la prueba de la no existencia de Dios.

Levi: Existe Auschwitz, por lo tanto, no puede haber Dios

(Camon, 1996, pp. 133-135).

En el texto mecanografiado, comenta Camon, Primo Levi agregó a lápiz: no encuentro una solución al dilema. La busco, pero no la encuentro. Meses después se suicidaría descerrajándose un tiro en la sien.

Como Levi, Elie Wiesel es también un superviviente de Auschwitz. Ambos coincidieron en aquel infierno, y en Todos los torrentes van a la mar, un relato estremecedor e imprescindible para entender el Holocausto, Wiesel le dedica dos páginas emocionadas. Hablábamos, discutíamos, confrontábamos nuestros puntos de vista y los argumentos que los sostenían, cuenta Wiesel. El tema en tomo a la existencia y a la insondable voluntad de Dios se vuelve recurrente, en medio del aquelarre de muerte y destrucción. Cierto día, cuenta Wiesel, pregunté al célebre rabí Menahem-Mendel Schneersohn si era posible creer en Dios después de Auschwitz. "¿Y cómo, después de Auchwitz, puede usted no creer en Dios? Pensé en lo que acababa de decir: ¿en quién más puede creerse? ¿No abdicó el hombre sus privilegios y sus deberes en Auschwitz? ¿No significa Auschwitz la derrota de la obra humana, el fracaso de la sociedad? ¿Qué nos queda, al margen de Dios, en un mundo dominado por las tinieblas de Auschwitz?" (Wiesel, 1996. p. 487). Después de Asuchwitz sólo es posible creer en Dios, porque la confianza en el ser humano ha quedado devastada. Vale para Wiesel la valiente reflexión de Jon Sobrino, un extraordinario teólogo, en las trincheras de Centroamérica, testigo de la persecución, la humillación y la muerte sistemática de sus conciudadanos, por motivos ideológicos, religiosos, entre ellos: "El que Dios deje morir a las víctimas es un escándalo irrecuperable, y la fe en Dios tiene que pasar por ese escándalo" (Sobrino, 1992, p. 24).

\section{Nosotros, los creyentes}

Primo Levi dice que no es creyente. No tiene razon: todos lo somos. No hace falta serlo de ningún credo para poder denominarse como tal. Todos somos creyentes. Lo somos, además, en un mismo sentido: en el de la posesión de un conjunto de ideas y posiciones rocosas sobre las cuales depositamos toda nuestra 
confianza y a las cuales concedemos un crédito completo, de acuerdo con la definición de la Real Academia. Somos creyentes porque tenemos nuestra mente amarrada a un repertorio de "convicciones mostrencas", en palabras de Ortega, que cumplen una función vital para nuestra existencia. Además de servir para orientarnos, en medio de la vorágine que nos rodea, Ortega cree, con razón, que nos ahorran la pesada y aburrida tarea de tener que ocupamos y preocuparnos de los hechos: la realidad es simple y llanamente aquello en lo que creemos. El filósofo mexicano Luis Villoro habla también de convicciones, cuando hace referencia a las creencias: "Convicciones son las creencias que integran nuestra personalidad, cumplen nuestros deseos profundos, obedecen a un proyecto vital, satisfacen intereses permanentes, otorgan a la vida un sentido" (Villoro, 1998, p. 119).

Hay razones, pues, para pensar que las creencias constituyen un capítulo central en nuestra vida personal y social. A las cuales acabamos de mencionar hay que añadir otra: las creencias tienen línea directa con los valores, y eso ya son palabras mayores, porque estamos hablando de estándares de conducta, que gulan regularmente nuestras acciones, en direcciones preferidas y preferentes. Creencias y valores son, pues, un repertorio de ideas obstinadas y redondas, que constituyen el armazón de nuestra mente y marcan el camino que ha de seguir nuestro comportamiento. A decir de dos de sus más cualificados estudiosos, Martin Fishbein e Icek Azjen (1975, p. 14), son "los bloques fundamentales de nuestra estructura conceptual". Las creencias tin̄en de significado el mundo que nos rodea, definen los atributos de los objetos que lo componen y constituyen la base informativa de las actitudes, de las intenciones y de la conducta. Son, en una palabra, una herramienta de la cual nos ayudamos para comprender y hacer inteligible la realidad que nos rodea. No hay posibilidad de concebir al ser humano libre de creencias, porque ello supondría la posibilidad, a todas luces inverosímil, de pensar en la "persona", psicológicamente hablando, al margen de lo social.

Dicho esto, es necesario añadir que las creencias religiosas han ocupado un protagonismo especial, en la construcción de la estructura mental. En las sociedades occidentales, lo han hecho mucho más antes que ahora, de suerte que cuando Moritz Lazarus y Hermann Steinthal, mediado el siglo XIX, intentan darle los apellidos al que sería su concepto más emblemático y más arriesgado, el Volksgeist (la existencia de un alma o mente colectiva; una suerte de estructura psicológica inmanente al grupo, a todo un pueblo, a una nación o a una comunidad), acuden a tres componentes recios: el lenguaje ("modos distintos de hablar no son sino manifestaciones de formas distintas de pensar", escriben), las costumbres y las creencias religiosas.

La presencia de las creencias religiosas en la arquitectura de la mente tiene en Emilio Durkheim uno de los representantes más cualificados, y eso es mucho tener. El francés, sin duda uno de los pesos pesados en toda la historia de la 
ciencia social, lanza una hipótesis de largo alcance, que cabría desglosar en los siguientes párrafos.

Los primeros esquemas mentales de los que se valió el ser humano para comprender y hacer inteligible la realidad, "los primeros sistemas de representaciones que el hombre se ha hecho del mundo y de sí mismo, son de origen religioso" (Durkheim, 1993, p. 39). A veces son los primeros y los últimos, o lo que es lo mismo, los únicos sisternas de representación. Son creyentes en estado puro y en estado ingrávido: sus convicciones no se sienten concernidas por nada de lo que acontece a su alrededor. De entrada, éste es un hecho que nos resulta indiferente; de salida, se trata de un hecho cuyas consecuencias, tanto para la persona en cuestión como para su entomo, no han sido, precisamente, alentadoras, por decirlo con suavidad.

Contrariamente a lo que acostumbramos a suponer, estas categorías de pensamiento no son individuales, sino "esencialmente colectivas: traducen ante todo estados de la colectividad" (Durkheim, 1993, p. 50); son representaciones colectivas, en el sentido que el maestro francés les da, en su conocido artículo de 1898.

Siendo asf, las creencias religiosas no pueden ser sino el "producto de una inmensa cooperación, que se extiende no sólo en el espacio, sino también en el tiempo; para construirlas, una inmensa multitud de espiritus ha asociado, mezclado y combinado sus ideas y sus sentimientos; largas series de generaciones han acumulado allí su experiencia y su saber" (Durkheim, 1993, p. 51).

Estos esquemas y sistemas de representaciones tienen una doble vertiente: interna-cognitiva y externa-activa. Las creencias propiamente dichas se sitúan en la primera, y los ritos en la segunda. "Las primeras son estados de opinión y consisten en representaciones; los segundos son determinados modos de acción" (Durkheim, 1993, p. 82). La acción sigue a la cognición: nos comportamos tal y como pensamos. Esta es una apuesta que, con independencia de la compleja y sinuosa trayectoria que ha tenido en el transcurso de la psicologfa, nos interesa sobremanera destacar, porque ella va a constituir el núcleo fundamental de la teorla de las actitudes'.

La vertiente funcional de las representaciones religiosas, que se concreta en actos y ritos colectivos, adquiere un nivel de significación psicosocial de primer

2. No es éste el momento para trater con detenimiento este asunto, pero la propuesta de Durkheim guarda un exquisito correlato con lo que décadas después propondrán los más cualificados téricos: la relación entre actitud y conducta. Durkheim lo expresa en los siguientes términos: "Las creencias religiosas son representaciones que expresan la naturaleza de las cosas sagradas y las relaciones que mantienen, sea unas con otras, sea con las cosas profanas. Por último, los ritos son reglas de conducta que prescriben cómo debe comportarse el hombre con las cosas sagradas" (Durkheim, 1993, p. 88). 
orden, porque a su vera nace y con su ayuda se alimenta la conciencia colectiva, el sentimiento de pertenencia, la cohesión, y lo que es más importante, la identidad social, y a su lado, la autoestima personal. "De modo que podemos asegurar por adelantado que las prácticas del culto, cualesquiera que sean, no son ni mucho menos movimientos sin sentido y gestos desprovistos de eficacia. Su función aparente es estrechar los lazos que unen al fiel con su dios, pero, al mismo tiempo, estrechan realmente los lazos que unen al individuo con la sociedad de la que forma parte (cursiva nuestra), pues el dios no es sino la expresión figurada de esa sociedad" (Durkheim, 1993, p. 371).

Muchas de las categorías que constituyen la osamenta de nuestra inteligencia tienen su origen en la religión. No hay razón para contravenir esta afirmación, pero ella nos invita a una pregunta inquietante: ies, entonces, el pensamiento religioso algo previo y distinto de las categorías esenciales de nuestro pensamiento? La respuesta de Durkheim es la acostumbrada: no, porque "la religión es una realidad eminentemente social. Las representaciones religiosas son representaciones colectivas que expresan realidades colectivas... Si las categorias tienen un origen religioso, deben participar de la naturaleza común a todos los hechos religiosos: deben ser, ellas también, realidades sociales, productos del pensamiento colectivo" (Durkheim, 1993, p. 41), es decir, algo compartido y "externo" al sujeto, y eso nos pone en un disparadero mucho más existencial que esencial, mucho más histórico que natural; en un disparadero religioso, derivado de lo psicosocial, y no al revés.

Dos ideas merecen nuestra atención. Por mucho que la vivencia de la fe forme parte de la experiencia personal más singular e intransferible, el hecho religioso es un hecho de la conciencia, forma parte de los procesos psicológicos superiores a los que otro gran maestro, este ruso y dedicado a la Psicología, Lev Vygostki, definió como procesos que van desde el exterior al interior del sujeto; procesos que primero tienen una vigencia interpersonal para pasar después a lo personal. No hay razón para pensar que las creencias religiosas sean una excepción. Más bien, todo lo contrario, se trata, muy probablemente, del mejor ejemplo de la "ley genética del desarrollo cultural" , de la ley fundamental de la psicología, de acuerdo con la cual “... el niño comienza a utilizar en relación consigo mismo aquellas formas de conducta que al inicio otros le aplicaron a él. El niño asimila las formas sociales de actuación y las traslada a sí mismo" (Vygotski, 1987, p. 157). De afuera hacia adentro: ése el camino que sigue el desarrollo de la conciencia, de acuerdo con el principio de que "detrás de todas

3. Los términos en los que el propio Vygotski define esta ley son los siguientes: "cualquier función en el desarrollo cultural del niño aparece dos veces, en dos planos: primero como algo social, después como algo psicológico; primer entre la gente, como una categorfa interpsiquica, después, dentro del niño, como una categoría intrapsiquica" (Vygotski, 1987, p. 161). 
las funciones superiores, de sus relaciones, están, genéticamente hablando, las relaciones sociales, las relaciones reales entre la gente" (Vygotski, 1987, p. 161), relaciones reales entre gente real que, luego, dan lugar a experiencias personales que, ahora sí, pueden ser todo lo singulares e intransferibles que se quiera.

Llevamos décadas (desde los años veinte del pasado siglo, con Lev Vygotski y Kurt Lewin a la cabeza; después vendrían Mead, Asch, Tajfel, Zimbardo, Gergen, Martín-Baró, entre otros), huyendo del individualismo psicologicista, que sitúa la llave de la mente, la conciencia y el comportamiento, tanto del llamado normal como aquel otro al que definimos como patológico, dentro de un modelo de sujeto encapsulado en sí mismo, suspendido en el vacío social, capaz de pasar, como si levitara, sobre las circunstancias que lo rodean (sobre las relaciones de poder, sobre las figuras de autoridad, sobre la presión de los grupos a los cuales pertenece, sobre las condiciones en las cuales se desenvuelve su existencia, sobre las normas y costumbres que nos atañen como miembros de una determinada comunidad, sobre el dolor, sobre el amor, sobre la muerte...): un hombre sin atributos, porque estamos hablando de un modelo (más que modelo, casi podríamos decir "molde") de sujeto único y universal que, en razón de su generalidad, se ve forzado a ser definido con trazos forzosamente gruesos y esquemáticos. Huimos del sujeto único y nos acercamos, de manera definitiva, al sujeto socio-histórico, a un sujeto inserto dentro de una cultura (Vygostki) o de una o varias subculturas, que forma parte de un contexto inevitablemente formado por categorías sociales (Tajfel), que debe al grupo su razón de ser (Lewin), que es capaz de relacionarse con otros sujetos, y en esa relación, se transforma en ser humano (Asch); un sujeto capaz de un juego todavía más sutil: el juego de mirar hacia dentro (de verse a sí mismo) sólo si y porque está dotado de herramíentas para mirar a su alrededor (el sujeto reflexivo de Mead). Un sujeto que se desenvuelve dentro de un contexto histórico (Martín-Baró), en el cual está presente el poder, la presión, la influencia, etc.

En el campo de lo religioso también conviene huir, acompañados de Ignacio Ellacuría y Ernst Bloch, cada uno de una mano para andar sobre seguro, del peligro de la "interiorización individualista", una interiorización cercada por los límites del propio individuo, cerrada a cal y canto al exterior, que es de donde siempre ha venido el pecado; una interiorización del mundo de la repetición o del siempre-lo-mismo, que decía Bloch. Conviene orillar también ese molde que, como por arte de magia, nos ofrece un sujeto sobrenatural estático y permanente (por su deuda con una supuesta naturaleza humana), en el cual la experiencia biográfica e histórica pasa desapercibida, un ser esencial (frente a lo existencial) y cerrado desde el momento metafórico de la creación; un ser que da vueltas en el cosmos, buscando la puerta por la que colarse, en su salvación eterna. Ese molde de sujeto es, sencillamente, una entelequia. "No hay hombre sin tierra. No hay novedad del hombre sin novedad en la tierra", sentencia Ellacuría (2000, p. 613). 
El sociólogo alemán Norbert Elias, con la sencillez y la sutileza de la que siempre hizo gala, lo dejó magistralmente descrito, a finales de los años treinta: "El ser humano es capaz de decir 'yo' porque y si es al mismo tiempo capaz de decir 'nosotros'. Ya la idea 'yo soy', cuanto más la idea 'yo pienso', presuponen la existencia de otras personas y la convivencia con otras personas; en suma, presuponen un grupo, una sociedad" (Elias, 1990, p. 82). Lo mismo podríamos decir de la idea "yo creo"; también a ella le debemos presuponer la idea de un "nosotros". En cualquiera de sus acepciones, el "yo" presupone un "nosotros" y un "ellos": un principio que ha sido santo y seña de la perspectiva psicosocial de todos los tiempos. Los procesos psicológicos (y el "yo" es el más distintivo de ellos) son, por encima de cualquier otra consideración, fenómenos relacionales, obedecen a una filosofía de la interacción y de la interdependencia, en virtud de la cual la unidad de análisis deja de estar ubicada en esos rasgos y características que diferencian a unas personas de otras, para situarse en la relación que mantenemos unos con otros, dentro de un contexto, en ese cruce de caminos entre naturaleza e historia, sujeto-mundo, mundo natural-mundo cultural, objetivación-desobjetivación, hecho en sí-hecho percibido. Solomon Asch, uno de los grandes teóricos del comportamiento grupal, describe con sencillez y contundencia esta propuesta: "el hecho capital consiste en que los hombres no se relacionan solamente con los objetos de la naturaleza, sino con otros hombres y que, en tal encuentro, se transforman en seres humanos" (Asch, 1962, p. 129).

La compleja trama de creencias, normas, valores e ideologías de que dispone el mundo de hoy no ha podido ser fruto de seres solitarios recluidos y aislados, cada uno en su habitáculo particular. Las creencias religiosas tampoco. La religión no es cosa de los dioses, sino de los hombres, de la inmanente socialidad del sujeto psicológico. De ahí su diversidad, su variabilidad, e incluso sus contradicciones. Se trata de creencias que no están irremediablemente cosidas a lo unívoco, sino a lo relativo, a la cultura y a la historia; porque no pertenecen a un sujeto universal sin atributos, sino a un sujeto socio-histórico; porque no están cerradas sobre sI mismas, sino abiertas al mundo, porque no están aisladas, sino en contacto permanente, hoy más que nunca, con ideas y convicciones distintas, porque no están cosidas a la esencia inmutable de la naturaleza humana, sino a la variabilidad de los acontecimientos que el hombre ha ido protagonizando, y a la experiencia de seres concretos, atravesados por diferentes peripecias biográficas.

¿Dónde queda, entonces, la verdad revelada, esa verdad absoluta que tiene vocación de eternidad? ¿Dónde quedan las cosas relacionadas con el mundo de la mente: en la historia? "El presupuesto fundamental de la revelación estrictamente tal y de la fe que responde a ella es la existencia de una inteligencia y de una voluntad, de una aprehender la realidad y de un optar desde ella" (Ellacuría, 2000 , p. 602). Normalmente, esa verdad ha quedado también en manos de los hombres, prueba de ello son al menos los tres siguientes hechos: (a) esas verda- 
des reveladas con vocación de eternidad han sufrido cambios, algunos de ellos muy significativos, a lo largo de la historia. Parece indudable que las creencias se acomodan a los signos de los tiempos. Más vale así, aunque a veces, esto sucede con una lentitud exasperante; b) hay determinados colectivos dentro de las religiones, en especial dentro de la religión católica, que piden a gritos cambios igualmente significativos, entre ellos, la posibilidad de que las mujeres puedan ejercer el oficio sacerdotal; c) las distintas religiones, las tres religiones monoteístas, por ejemplo, defienden verdades reveladas de muy distinto cariz, y todavía más, defienden verdades contrapuestas, todas ellas, de hecho, en nombre de Dios. La verdad revelada es, pues, algo que está mediado por la mano del hombre y sigue el camino que le marca el devenir, y sobre todo, las necesidades y los intereses de cada uno de los momentos de la historia. Hay una realidad histórica, decía Ignacio Ellacuría, "en la cual interviene Dios y en la cual interviene el hombre, de modo que no se da la intervención de Dios sin que en ella se haga presente, de una u otra forma, el hombre y no se da la intervención del hombre sin que en ella se haga presente la intervención de Dios" (Ellacuría, 1991, p. 327).

Hablamos entonces de una verdad históricamente revelada, que pone contra las cuerdas creencias y ritos que no se adecuan a los signos de los tiempos, porque atentan contra principios y valores que se han erigido en fundamento de nuestra convivencia: la Declaración Universal de Derechos Humanos, la Declaración Universal sobre los Derechos del Niño, la Declaración del Derecho del Ser Humano a la Paz, etc. Ya lo advirtió Gustavo Gutiérrez, al hablar de la ortopraxis, buscamos "equilibrar e incluso rechazar el primado y casi exclusividad de lo doctrinal en la vida cristiana, y sobre todo el esmero - muchas veces obsesivo - en procurar una ortodoxia que no es, a menudo, sino fidelidad a una tradición caduca o a una interpretación discutible" (Gutiérrez, 1975, p. 33), una fidelidad por lo concluso, una afición, malsana la mayoría de las veces, por los espacios cerrados a cal y canto y faltos de ventilación, una absurda manía por dar vueltas cansinamente a una noria que lleva décadas sin dar una gota de agua, pero que sirve a los intereses interesados de unas pocas personas, todas ellas varones de pelo en pecho que se resisten como gato panza arriba a perder su situación de poder porque, en un horizonte abierto, pasarían por completo desapercibidos.

En su acepción más general, la historicidad de las creencias es una obviedad, que no requiere ya de nuestra atención. Sin embargo, cuando aplicamos este elemental principio a las creencias religiosas, se enconan las posiciones, de manera incomprensible, porque cuesta mucho trabajo entender la compatibilidad de lo "revelado" con lo "adaptado" al momento histórico. Y así nos va: de mal en peor, sobre todo cuando vemos cómo determinadas creencias religiosas suscitan un amplio desinterés. En una de sus propuestas más singulares y lúcidas, Ignacio Ellacuría había defendido una postura que, cada día que pasa, tiene un mayor poder de convicción: no es incompatible el carácter histórico de los hechos salvíficos con el carácter salvífico de los hechos históricos; solo es necesario 
disponer de una suficiente flexibilidad mental para poder entenderlo y aceptarlo. Para un científico social, como es el caso del autor de estas páginas, este principio de reversibilidad de los fenómenos psicológicos vuelve a ser una obviedad. Por la sencilla razón de que los dualismos excluyentes han periclitado epistemológicamente hace muchos años, y hoy en día, ya no tiene sentido, ni desde el punto de vista teórico, ni aplicado, contraponer el grupo o la sociedad a los individuos, el cuerpo a la mente, la cognición a la emoción. Y, como es lógico, tampoco tiene lugar contraponer la historia profana a la historia sagrada, la historia natural a la historia sobrenatural. Lo que hay que contraponer es la verdad a la mentira, la justicia a la injusticia, la vida a la muerte, situaciones y estructuras que favorecen la salud y el bienestar a aquellas otras que promueven el trastomo y la enfermedad. Lo que hay que contraponer es el pecado a la gracia, pero hacerlo también en lo concreto.

La diferencia fundamental no es entre naturaleza y sobrenaturaleza, una vez entrados en la única historia de Dios que, en la misma creación del hombre, lo ha elevado a participar personalmente de su propia vida divina, sino entre gracia y pecado. Hay acciones que matan la vida (divina) y hay acciones que dan la vida (divina); aquéllas son el reino del pecado; éstas son el reino de la gracia. Hay estructuras sociales e historicas que son la objetivación del poder del pecado y, además, vehiculan ese poder en contra de los hombres, de la vida de los hombres, y hay estructuras sociales e históricas que son la objetivación de la gracia y vehiculan, además, ese poder a favor de la vida de los hombres; aquéllas constituyen el pecado estructural y éstas constituyen la gracia estructural (Ellacuría, 1991, p. 356).

Ellacuría nos pone contra las cuerdas: acciones, muchas de ellas fundamentadas y apoyadas en creencias y valores, que llevan dentro de sí el signo inequívoco del mal. La pregunta entonces, ya no es si las acciones se apoyan o no en creencias, sino por los criterios que utilizamos para creer en las creencias.

\section{2. ¿Son creibles las creencias?}

Un día de septiembre de mediados de los años cuarenta, el Herald de Lake City (Estados Unidos) recogía la siguiente noticia: "De acuerdo con los mensajes procedentes del planeta Clarion recibidos por la Sra. Marian Keech, la ciudad de Lake City desaparecerá el 21 de diciembre a consecuencia de una inundación... [que] creará un mar interior que se extenderá desde el Círculo Ártico hasta el Golfo de México. Al mismo tiempo, un cataclismo hará desaparecer la costa oeste, desde Seattle hasta Chile" (Festinger, Riecken y Schachter, 1956, p. 31). La mayorla de los ciudadanos de Lake City hizo caso omiso del estrambote, pero no faltó un reducido grupo en quien la profecía de la señora Keech hizo mella. Una excelente ocasión, pensó Leon Festinger, uno de los teóricos más fértiles de la psicología, para vivir de primera mano una peripecia que se presumía apasionante. 
El día 21 por la mañana, la vidente recibió instrucciones muy concretas: pasada la media noche, llegaría un platillo volante para rescatar a quienes habfan confiado y creído en la veracidad de la profecía. A las 11:15 de la noche, se recibe un nuevo mensaje: cojan los abrigos y permanezcan sentados y en silencio. A las 11:30, todo está listo. No hay más que esperar la señal, pero como era previsible, no sucedió nada. A pesar de ello, aquel intrépido grupo de creyentes en creencias esotéricas siguí confiado en un milagro el cual, finalmente, no llegaría. Hacia las 3 de la mañana del día 22, tras un reconfortante café, el grupo tomó conciencia de que "en adelante, el problema consistía en tranquilizarse y tratar de encontrar una manera adecuada y satisfactoria de reconciliarse con el varapalo que habian recibido sus creencias" (Festinger, Riecken y Schachter, 1956, p. 167). ¿ Habrían errado en la fecha? ¿Habrían interpretado de forma errónea el mensaje? Ninguna de las dos cosas. Lo que sucedió es que el mundo se libró de la destrucción gracias a su fe inquebrantable y a sus buenos oficios. Ese fue el contenido del mensaje transmitido por la señora Keech, al filo de las cinco de la madrugada, y ello les obligaba a convertirse en portadores de una noticia que, a las puertas de la Navidad, pasaría a convertirse en la verdadera buena nueva.

El estudio de Leon Festinger ha pasado a la historia de la psicología como una de las investigaciones más emblemáticas, y a él conviene recurrir siempre que estén de por medio las creencias y las actitudes. La conclusión no se hace esperar: todas las creencias, por muy extravagantes o estrambóticas que puedan parecer, son susceptibles de tener un público que las asuma como propias y las incorpore a sus convicciones, y una vez asumidas, las abrace como si les fuera la vida en ello. Un día de estos, el periódico marroquí Attajidid, vinculado a un partido islámico, reiteraba otra extravagancia macabra, que alimenta creencias inverosímiles: el maremoto que devastó, a finales del 2004, el sureste asiático, es un castigo divino por el comercio sexual que se había instalado en algunas de estas zonas turísticas. Miles de fieles creen a pie juntillas esta interpretación de los hechos y no habrá manera de que se apeen de sus convicciones, porque "una persona convencida es una persona difícil de cambiar. Si le dices que estás en desacuerdo, volverá la cara. Si les das datos o imágenes, cuestionará la fuente. Si apelas a la lógica, será incapaz de ponerse en tu lugar": así dan comienzo su estudio Festinger, Riecken y Schachter (1956, p. 3).

Aunque parezca una tautología, las creencias no existen, porque y cuando son creibles, y dejan de existir, porque y cuando son absurdas o fantasiosas. Las creencias existen, sencillamente, porque son creídas más allá de lo que pueda hacerlas verosímiles o inverosímiles. Esa es, junto a la de su invulnerabilidad ante los hechos, una de las conclusiones del estudio al cual acabamos de aludir. La otra es que las creencias suelen ser muy funcionales. Sirven, ya lo hemos dicho en el epígrafe anterior, para dotar de sentido y coherencia los acontecimientos que nos rodean, para comprenderlos e interpretarlos. Es perfectamente 
razonable, pensaban las gentes del grupo presidido por la señora Keech, que sobrevenga un cataclismo, en este mundo abocado al desconcierto y al pecado, y resulta perfectamente razonable lo contrario: que el mundo se salve, gracias a la intervención y la excelente disposición de algunas personas de buena voluntad. Las creencias se acomodan con suma facilidad a la fluctuación de los hechos.

Si todas las creencias son igualmente creíbles (susceptibles de ser creídas, debiéramos decir con más precisión), lo que nos interesa indagar son los criterios y las razones para ser creídas, para ser seguidas, a veces con tanta obstinación, para ser defendidas con tanto ardor. Bien mirado, lo de Lake City no deja de ser una broma, frente a la macabra aventura que iniciara a comienzos de los setenta Jim Jones, aquel sombrío personaje que irrumpió en la ciudad de San Francisco como líder de un denominado Templo del Pueblo. Acosado por las autoridades, debido a sus irregularidades financieras, se instaló con sus fieles en un paraje medio selvático de la Guyana, y en una noche aciaga de noviembre de 1978, provocó un suicidio colectivo: 913 de ellos murieron al ingerir de forma voluntaria un bebedizo mortal. Más allá de las muchas consideraciones hechas al respecto, en torno a la personalidad del tal Jones, de su capacidad de persuasión, de su carisma, etc., nos interesan sus seguidores, y algo podemos decir sin temor a equivocamos. Estamos hablando de creyentes en estado puro que, desde nuestro punto de vista, distan mucho de ser considerados como creyentes ejemplares. He aquí un caso (y como éste los hay a miles) de creencias que conducen directamente al abismo, y eso nos debe abrir de par en par los ojos a una realidad: las creencias no nos inmunizan contra nada, ni siquiera contra el mal radical, ése del que hablara Kant, en tono tan severo.

Las creencias no nos inmunizan contra el mal. A veces parece todo lo contrario. Es, precisamente, su exceso el que se encuentra en el fondo de algunas de las tribulaciones más desastrosas que ha sufrido la humanidad, a lo largo de su historia. Ese es el argumento que desgrana Rafael del Águila, en el primer capítulo de una monografía que se adentra en los secretos de la violencia política y del terrorismo, como el que nos invadió el 11-M. Una parte nada despreciable de esos 187 millones de muertos con los que cerró su sombría trayectoria el pasado siglo XX, ha sido causada por personas, no sabemos si de buen corazón. pero animadas. sin duda, por buenos propósitos. De pronto, dice del Águila (2005), nos damos cuenta que Bin Laden mata por altos ideales, lo mismo que hacen los terroristas etarras y los autores de los atentados terroristas del II de marzo de 2004, en Madr: i, y se nos repite, por activa y por pasiva, que la guerra de Irak tiene como objetivo instaurar la democracia, en el mundo. Cuando creencias tan distantes de personajes y grupos tan diferentes conducen al mismo callejón, a ese callejón sombrío de la humillación, de la sumisión, de la tortura y de la muerte, entonces, se hace necesario revisar el propio concepto de creencia, su naturaleza, la legitimidad de los objetivos que persiguen, o los medios de los 
cuales se sirven para conseguirlos. Entonces es cuando cabe seriamente hacerse algunas preguntas. De entrada, por lo menos dos: los motivos que tenemos para creer y la legitimidad de las creencias. Puede que sea sólo una, pero éste es un detalle que, como veremos de inmediato, resulta banal, dado el fondo de los asuntos, que estamos manejando.

A la primera podemos responder con la ayuda de Luis Villoro. Hay dos razones fundarnentales para "creer" en algo: la procedencia de la creencia y los motivos que nos impulsan a seguirla. Cabe holgadamente la posibilidad de que a las creencias les suceda lo que les ocurre a las demandas y las órdenes procedentes de una figura de autoridad: tienen mayor probabilidad de ser seguidas (creídas), en la medida en que se perciba que proceden de una fuente legítima. Es la legitimidad, real o percibida, como criterio para seguir a pie juntillas una creencia. Esa es una apuesta seria. En el terreno de las creencias religiosas, no es sólo una razón, sino "la razón" primordial y por excelencia. Detrás de ella, apoyándola con decisión, se encuentra una de las más sólidas y mejor trabajadas hipótesis de la teoría de la comunicación: la credibilidad de la fuente como marco y motivo para la persuasión, como razón para creer. Bien mirada, es una hipótesis que rondaba la propuesta del mismo Ortega, al definir la creencia como el "crédito completo que se presta a un hecho". Para el caso que aquí nos ocupa, nos basta con saber que la fuente de persuasión es uno de los criterios que los destinatarios de un mensaje utilizamos para dar crédito a su contenido, y que hay dos condiciones concretas que nos impelen a ello: la competencia o experiencia atribuida a la fuente y la fiabilidad (veracidad, sinceridad) y confianza que depositamos en ella.

Las creencias religiosas se someten a este mismo principio de manera muy sensible. Su procedencia se convierte en el motivo primordial para adoptarlas y adecuar nuestra vida a ellas, ya que su origen reúne sobradamente todos y cada uno de los requisitos de competencia, fiabilidad, experiencia y confianza. De hecho, los reúne, en grado máximo y, en la práctica, incomparable, porque estamos hablando de fuentes de persuasión, emanadas de la divinidad, donde no cabe el error, ni la falsedad, y donde están garantizadas una exquisita ecuanimidad, la justicia y la verdad. Si la primera razón para creer tiene que ver con los antecedentes, la segunda, dice Villoro (1998), hace hincapié en los motivos que los seres humanos utilizamos para creer. Éstos pueden ser casi infinitos, pero los que, en realidad, marcan el camino de nuestras acciones son aquellos que tenemos amarrados al curso de nuestra experiencia, a nuestro proceso de aprendizaje e incluso a las características de nuestra peripecia biológica, psicológica o social.

Durkheim entra en liza y nos ofrece su visión particular que, conociendo bien su trayectoria teórica, no puede ser otra que la que es: los criterios de autoridad que se encuentran detrás de las creencias, se reducen al refrendo social, de suerte que "una representación colectiva, por ser colectiva, presenta ya las garantías de la 
objetividad, pues no sin motivo se ha podido generalizar y mantener con la suficiente persistencia" (Durkheim, 1993, p. 682). La naturaleza compartida de la creencia como motivo para su seguimiento parece una tautología, porque, en puridad, no podriamos hablar de creencias, salvo cuando sean compartidas, y en ese caso, todas las creencias, por el mero hecho de serlo, contarian ya con la garantía de objetividad.

Este es un marco de y para las creencias, pero no es el único, y desde nuestro modesto punto de vista, tampoco es el más importante. Los hay mucho más decisivos: todos aquellos que se sitúan en la imprescindible pertenencia y participación de las personas en grupos, organizaciones e instituciones, en las normas que las rigen, en la autoridad que las gobieman, en las tareas que se nos encomiendan, en la estructura que las definen. Es necesario reseñar que de entre el cúmulo de motivos para creer, éste es de una especial relevancia y contundencia y de una escasa atención. El punto de partida se nos antoja susceptible de poder ser aceptado sin excesiva controversia: las creencias ejemplifican, probablemente como ningún otro, ese proceso de fuera hacia dentro que, según Vygotski, sigue el desarrollo de las funciones psíquicas superiores.

No han sido éstos los motivos que más interés han despertado, pero cabría la posibilidad de considerarlos como los motivos más importantes para creer, máxime si tenemos en cuenta la fuerza del grupo, en la construcción de una parte de las metáforas que adoman nuestra mente, ésa que nos capacita para interpretar, explicar, anticipar y entender el mundo que nos rodea y la conducta de nuestros congéneres` (Rivière, 1991). Es necesario recuperar las creencias grupales, esas "convicciones que los miembros de un grupo son conscientes de compartir y a las que consideran definitorias de su pertenencia grupal" (Bar-Tal, 1996, p. 256), aquellas que son consideradas como definidoras de la esencia del grupo, marcan la senda de las actitudes y los comportamientos de sus miembros, nos señalan como pertenecientes a él, al tiempo que nos diferencian de otros. El grupo como motivo (y como presión) para creer. Esa es una hipótesis que merece ser tomada muy en consideración, entre otras razones, porque detrás de ella, con frecuencia, encontramos la imperiosa necesidad de satisfacer necesidades emocionales de primer orden, entre ellas, la de identidad, que sólo encuentran cauce dentro de los grupos primarios. Es una relación de puro intercambio: abrazo las creencias y (porque) el grupo da satisfacción al apego, al apoyo emocional, a la autoestima, etc.

4. Atribuimos intenciones a otros, inferimos lo que piensan, lo que sienten, lo que creen, lo que desean, comunicamos nuestros pensamientos y comprendemos los de los otros y nos adaptamos a lo que saben y a lo que ignoran: de todo eso son capaces los objetos con mente que somos los humanos (Rivière, 1991, p. 148). 


\section{El principio-emancipación}

La grupalidad concede carta de naturaleza a las creencias, pero no necesariamente de legitimidad o veracidad. En la búsqueda de estos criterios, nos topamos con una de las hipótesis que mayor nivel de consenso ha llegado a alcanzar entre los científicos sociales: "las grandes ideas de las ciencias sociales tienen invariablemente sus raíces en aspiraciones morales. Por abstractas que las ideas sean a veces, por neutrales que parezcan a los teóricos e investigadores, nunca se despojan, en realidad, de sus orígenes morales" (Nisbet, 1969, p. 33). La ciencia social, en general, y la psicología, más en particular, entienden que no da igual ocho que ochenta, y que no todas las creencias responden a la aspiración moral que debe presidir el quehacer del científico social, una aspiración que quedó clara y patente en la propuesta de sus padres fundadores - Comte, Marx, Durkheim, Weber, Tönnies, etc. Todos ellos, desde posturas teóricas no siempre coincidentes y desde posiciones ideológicas, en algunos casos, claramente divergentes, coincidieron en la necesidad, de señalar primero, para cambiar después, aquellas condiciones que conducían a un deterioro de la vida social y de la salud física de millones de personas, a raíz de los cambios tecnológicos que incorporaban al sistema productivo. La emancipación como objetivo: ese es el acuerdo básico. Es más, dice Brian Easlea, un doctor en física matemática, que profesa como catedrático en la Universidad de Sussex, "la distinción más importante que puede plantearse entre las ciencias físicas y las sociales es que, si bien carece de sentido hablar de la liberación de los electrones, sí que tiene un sentido muy oportuno hablar de liberar a la gente o, posiblemente, de liberar a alguna y oprimir a otra" (Easlea, 1977, p. 208).

¿Liberarlas de qué? Esa es la pregunta que persigue a la ciencia social, desde los tiempos de Comte. A lo largo de estas páginas ya hemos avanzado una respuesta: de aquellas creencias, no importa de donde procedan, ni el apoyo que sean capaces de congregar, que entienden necesario aplastar, humillar, perseguir y devorar física y psicológicamente a personas que no comparten nuestro credo. $Y$ si esas creencias están dictadas por algún dios, entonces lo que se hace necesario es liberar a las personas de los dioses, cuya razón de ser se sustenta sobre la persecución y la humillación, porque detrás de esas creencias se encierra una profunda deslealtad con el ser humano, o con la humanidad de las personas. Ese sería uno de los argumentos de aquel sutil pensador que fue Max Horkheimer, la emancipación tiene un correlato con esa teoría que se muestra crítica con la autonomía absoluta de un ego aislado y con el principio que la sustenta: una individualidad ajena al acontecer del mundo. En este terreno, sigue la huella de Comte, para quien el primer paso de la emancipación consiste, precisamente, en orillar todas aquellas creencias pre-científicas, que se usan para la explicación de los hechos concernientes a la sociedad y al comportamiento de las personas. Horkheimer afina un poco más su punto de mira, para centrarlo en la improcedencia de un sujeto de 
espaldas al mundo. Pero lejos de quedarse ahí, da un paso muy significativo: una teoría crítica de la sociedad "no posee otra instancia específica que el interés, ínsito en ella, por la supresión de la injusticia social" (Horkheimer, 1974, p. 270). Lo podemos decir más alto, pero difícilmente lo podremos decir más claro. Sería bueno advertir que se trata de una crítica hacia dentro de la propia teoría (creencia en un ego autónomo y en una individualidad ajena al acontecer socials), pero también hacia fuera: también es una crítica contra situaciones y estructuras que crean o favorecen la injusticia.

Con la ayuda del principio misericordia, que recoge una colección de artículos, publicados a lo largo de la década de los ochenta, la década tenebrosa de El Salvador, Jon Sobrino se suma por entero al principio-emancipación. Toma como punto de partida una cita de la carta de Pablo a los Romanos, que lleva impresa la doble vertiente de la crítica a la cual estamos aludiendo y la concreta en dos principios de un hondo calado: verdad (crítica hacia dentro) y justicia (crítica hacia fuera): "la cólera de Dios se ha revelado contra aquellos que aprisionan la verdad con la injusticia". En tomo a ella, va desgranando una serie de argumentos con cuya ayuda aborda una tarea tan arriesgada como necesaria, si no queremos seguir dando pasos de gigante hacia el abismo: la necesidad de rescatar, de entre la masa informe de hechos que nos rodean, algún criterio de verdad. Para el téblogo salvadoreño, la única manera de liberar la verdad de las garras de quienes la tienen aprisionada reside en recuperar una actitud de honradez con lo real, y ahí es donde se encuentra, probablemente sin pretenderlo, con Horkheimer, quien no es precisamente una mala compañía, para volver a aquel principio de caridad de la teología de la liberación: la realidad y no las ideas como punto de partida, "hay que dejar a la realidad ser lo que es para captarla y oírla tal cual es" (Sobrino, 2003, p. 67).

$\mathrm{Y}$ eso significa varias cosas: hay que mirar y escuchar la realidad sin manipularla, o lo que es lo mismo, mirarla no a la luz de nuestras creencias, sino al calor de los hechos que ofrece; eso lleva, necesariamente, a evitar encubrirla, mediante la mentira institucionalizada y el engaño masivo como los que hemos sufrido, con argumentos estrafalarios, a raiz de la guerra de Irak o del 11-M, por poner ejemplos recientes; se hace necesario recuperar la historia y con ella, la memoria, porque tanto una como otra nos dirán que "...hay unas cosas reales más importantes que otras en las que poner la atención" (Sobrino, 2003, p. 89);

5. Dada la importancia del asunto que nos incumbe, merece la pena citar las palabras textuales: "El pensamiento crítico y su teoría se oponen a ambas actitudes. No son ni la función de un individuo aislado, ni la de una generalidad de individuos. Tiene, en cambio, conscientemente por sujeto a un individuo determinado, en sus relaciones con otros individuos y grupos, y en su relación critica con una determinada clase, y, por último, en su trabazón, así mediada, con la totalidad social y la naturaleza" (Horkheimer, 1974, p. 243). 
hay que dejarse afectar por el dolor y el sufrimiento, devolver la realidad a las víctimas, "dejarse afectar, sentir dolor ante vidas truncadas o amenazadas, sentir indignación ante la injusticia que está detrás de la tragedia" (Sobrino, 2003, p. 36); lejos de un prurito estrictamente religioso, esa conmiseración para con el otro que sufre es la traducción más elemental de un proceso psicológico tan central como la empatía y el rol taking, decisivos ambos en el desarrollo moral, como muy bien se ha ocupado de mostrar y demostrar la psicología. Pero sabemos algo más, la empatía y la identificación con el otro (hacemos cargo de su situación y ser capaz de ponemos emocionalmente en su lugar) son procesos cuya relación con la conducta violenta y agresiva nos es de sobra conocida. En uno de los extremos de dicha conducta se encuentra la deshumanización de la víctima, que tanto y tan bien estudiada fue, entre otros, por Ignacio Martín-Baró, asesinado también en aquella estremecedora madrugada del 16 de noviembre de 1989. Con motivo del 60 aniversario de la liberación de Auschwitz, hemos tenido oportunidad de volver a estremecernos con el hortor. Daniel Goldhagen ${ }^{6}$ lo recuerda: "Hace sólo dos semanas un guardia alemán de Auschwitz confesaba la verdad a la $B B C$ : que recordaba su etapa en el campo con 'alegría'. Siempre tenías presente, confesaba, el hecho de que los judíos son enemigos... No surgía un sentimiento de simpatía o empatía. Los niños son el enemigo en este momento. El enemigo es la sangre que llevan dentro. Consideraba [el guardia] que matar judíos estaba bien".

La quiebra de la misericordia como raíz del mal. Daniel Batson lleva más de veinte años dándole vueltas a la compasión como una forma de empatía intrínseca, como algo con sentido y fin, en sí mismo, más allá del mero "cálculo hedónico", que definimos en términos de costos y beneficios. En el proceso de compasión (Batson, 1991) hacen acto de presencia tres procesos psicológicos de primera instancia: el apego (caridad), la empatía (piedad, compasión) y el altruismo. La compasión, como el principio misericordia, mira al exterior del sujeto, centra su mirada en el otro, es "una re-acción ante el sufrimiento ajeno interiorizado, que ha llegado hasta las entrañas y el corazón propios" (Sobrino, 1992, p. 33). Desde la psicología social, Martín-Baró se suma, de manera incondicional, a esta posición. En el transcurso del epígrafe, dedicado al altruismo, y como una crítica al cálculo hedónico, escribe:

Es importante, entonces, subrayar la existencia del altruismo y su irreductibilidad a actos solapados de egoísmo. Que se dan actos objetivamente altruistas, es reconocido por todos: personas que entregan su vida a los demás, desde la religiosa que consagra su vida al servicio de los enfermos, hasta el revolucionario que muere en la lucha por liberar a su pueblo. No se puede afirmar con seriedad que en estos casos haya una ganancia, una recompensa o un placer objetivo para estas personas, o que la estructura intencional de

6. "En el corazón de la oscuridad", El País, 29 de enero de 2005, p. 14. 
sus actos no busque directa y desinteresadamente el beneficio de los demás. Ahora bien, esto no quita para que la religiosa, el revolucionario o cualquier otra persona altruista pueda sentir la satisfacción subjetiva de servir a los demás, la paz de haber cumplido con sus ideales, aun a costa de su propio sacrificio. Este sentimiento puede ser y de hecho es recompensante, pero no en un sentido hedonista: dar la vida no es algo agradable bajo ningún aspecto, y tanto el héroe como el mártir la dan por sus ideales al servicio de los demás. No hay aquí una búsqueda personal - prescindiendo de casos masoquistas o alteraciones semejantes-, sino una entrega y subordinación de los intereses personales a un ideal (Martín-Bar6, 1983, p. 346).

Principio emancipación y justicia, principio realidad y compasión: éste es el argumento que venimos trazando. A él se suma Hans Küng, propugnando una ética mundial común, que no se identifique con una cultura, que nada tenga que ver con una determinada religión, y que pueda ser compartida por quienes defienden credos distintos y por aquellos cuyas creencias no miran, ni siquiera de reojo, a lo trascendente: "una actitud ética global, una ética mundial, no es otra cosa que el mínimo necesario de valores humanos, criterios y actitudes fundamentales" (Küng, 2000, p. 131). El té́logo alemán se acoge a los dos estándares que hemos visto en Sobrino: verdad y justicia. Ambos, justo es decirlo, siguen en este terreno la senda marcada por Michael Walzer, un prestigioso científico social, que profesa como catedrático en la Universidad de Princeton, quien, desde la década de los ochenta, viene defendiendo la existencia de un núcleo moral mínimo, que estaría compuesto por el derecho a la vida, el trato justo, la integridad física y la integridad psíquica. La propuesta de Küng, la de Sobrino y, huelga decirlo, la de Walzer, es la de que estos estándares están por encima de las religiones, y la pregunta que se nos plantea es saber en qué medida, los diversos credos que existen en el mundo, están dispuestos a renunciar a algunas de sus convicciones para garantizar este minimalismo moral, o supeditar alguno de sus preceptos para garantizar la vida o la integridad física y psíquica. La respuesta es desoladora, en la práctica, ninguno, aunque todos digan lo contrario. No hay noticias de que alguna religión esté dispuesta a renunciar a sus creencias para defender a cabalidad estos cuatro principios. Algunas de las interpretaciones de algunos credos justifican sin pudor incluso la muerte y el terror contra los que consideran enemigos de su fe, y no digamos lo que ocurre en el terreno del trato justo y de la integridad psíquica, ahí la vulneración de los principios éticos elementales es demoledora.

El interés cognoscitivo emancipatorio, que decía Habermas, nos incumbe a todos, y de manera especial, a los científicos sociales con independencia de nuestras creencias, y de si éstas tienen o no un fondo asentado en convicciones religiosas. Hemos visto algunas de sus manifestaciones: la mejora de las condiciones de vida, que deterioran y lastiman física y psicológicamente la existencia de amplias capas de la población; la mejora en la condición social de la clase trabaja- 
dora, de la cual hablaba Comte; la lucha contra la injusticia social, en palabras de la teoría crítica; la recuperación de la historia y de la memoria; la lucha contra la mentira ocultadora, y la empatía con el dolor de las víctimas como parte del principio misericordia, que enarbola Jon Sobrino, desde la teología. He aquI un listado nada peregrino del principio-emancipación. Pero hay algo más, emancipar no es solo luchar a favor de la paz y de la justicia; también es descubrir el funcionamiento de aquellos procesos que la impiden y de aquellos otros que la facilitan. $Y$ ahí es donde el quehacer del científico social se diferencia de otros procedimientos: allí donde unos actúan animados tan sólo por sus creencias, nosotros lo hacemos presididos por una sólida fundamentación teórica, ayudados por los datos que nos ha ofrecido la investigación llevada a cabo con el rigor requerido, animados por el contraste de nuestras hipótesis, y sujetos al implacable juicio de la comunidad científica.

La diferencia puede ser actuar dejándose llevar sólo por convicciones y movido por grandes ideas (la paz, la justicia, la verdad), o hacerlo siguiendo la huella del análisis, del examen riguroso de los hechos que nos ofrece la realidad'. Desde el primero de los supuestos cabría holgadamente la posibilidad de que las creencias nos pudieran arrastrar hacia algún abismo; desde el segundo, el peligro está conjurado de antemano, porque el punto de partida ya no está sólo en las convicciones, sino en los hechos, animados y teñidos, claro está, por creencias, pero nunca suplantados por éstas. Principio misericordia y principio emancipación son dos maneras de afrontar la realidad, los dos convergen en un punto que entendemos decisivo: sin renunciar a su reflexividad, ambos tienen la mirada puesta en el exterior, ambos se desembarazan de ese cómodo solipsismo, el cual se recrea en volver, una y otra vez, sobre sí mismo, en un acto de injustificado narcisismo, ninguno de ellos rinde culto, ni exclusivo, ni preferente a las creencias, sino al bienestar de los otros.

A veces, cuando se sigue la línea rígidamente marcada por las creencias, puede ocurrir lo mismo que cuando el necio coge una linde. La linde se acaba, pero el necio sigue. Desde el principio emancipación este peligro está conjurado de antemano, porque el camino se va haciendo al andar, porque hay veces que es necesario volver sobre los pasos ya dados y desandar el camino, porque éste tiene recodos, que es necesario escudriñar con todo detalle, porque a veces el camino es la meta (ftaca es, precisamente, el camino).

\section{Las víctimas: el principio-esperanza}

La vida de todos los hombres se encuentra cruzada por sueños soñados despiertos (Ernst Bloch).

7. Es Octavio Paz quien, en algún momento, de El laberinło de la soledad, maneja esta hipótesis: el examen y la crítica son las dos amas de las cuales se sirve el intelectual. 
El principio emancipación tiene vocación de hecho, pero se encuentra siempre en camino. Difícilmente puede ser una realidad completa. pero tiene la obligación de ser una línea dibujada en el horizonte con claridad; tiene tanto de utopía como de realidad. Es uno de esos sueños que soñamos despiertos, el cual se pone en marcha en el principio esperanza, del cual Emst Bloch da cuenta, en una de las obras soberanas del pasado siglo XX. La esperanza mira hacia uno mismo y dibuja, en el horizonte de nuestra vida, una línea de aliento; la misericordia mira hacia el otro que sufre para acompañarlo en su dolor y abrirle luego un camino de esperanza; la emancipación mira hacia el exterior de los sujetos y centra su atención en aquellas condiciones estructurales con un poder devastador sobre ellos, porque impiden dibujar horizontes de esperanza y anulan nuestra capacidad para entender el sufrimiento ajeno.

La esperanza se aprende, dice Bloch: a soñar también se aprende. Se aprende sobre todo a soñar despierto; se enseña a los niños, tan pragmáticos ellos, a trazar horizontes, más allá de la línea de la inmediatez; se permite que se pongan en el lugar del otro para ver los atardeceres; se los obliga, a ellos que son tan egoístas, a compartir; se les enseña a dejar las puertas abiertas, sin echar la cancela a sus sueños; se los anima a andar, a moverse sin miedo para ver, ofr y escuchar sones distintos; se los instruye en el valor de lo propio y el respeto de lo ajeno; se los incita a que intenten llegar, aunque se tengan que volver. Ya lo dijo Kurt Lewin, quien supo, desgraciadamente, mucho de estas cosas: la democracia necesita ser aprendida, no es algo que se nos conceda como un don de la naturaleza; se aprende a ser demócrata y se aprende a ser autócrata, y también se aprende a ser demócrata, después de ser autócrata. Afortunadamente, cambiamos. Se trata de aprender la esperanza, reitera Bloch. Y el Lewin, investigador de la norma grupal (de nuevo el grupo), nos echa una mano para saber cómo: nunca desde la obediencia y desde la sumisión, sino desde la independencia. Nunca solos y a título individual, sino desde el grupo y a título colectivo: del todo a las partes. Una excelente y sólida idea, a la cual la psicología ha dado una y mil vueltas: el grupo como instrumento de cambio. Se trata de aprender la esperanza.

La vida de todos los hombres se halla cruzada de sueños soñados despiertos. Una parte de dichos sueños es simplemente una fuga banal, también enervante, también presa para impostores; pero otra parte incita, no pernnite conformarse con lo malo existente, es decir, no permite la renuncia. Esa otra parte tiene en su núcleo la esperanza y es transmisible (Bloch, 2004, p. 26).

Pero lo malo (o lo bueno, depende de cómo se mire) es que la desesperanza sigue los mismos pasos: también se aprende. Martin Seligman lo dejó por escrito, en una de las propuestas teóricamente más solventes de la psicología, en la segunda mitad del pasado siglo: la indefensión aprendida. Aprender la desesperanza. 
La indefensión es el estado psicológico que se produce frecuentemente cuando los acontecimientos son incontrolables. ¿Qué significa el que un acontecimiento sea incontrolable? ¿Cuál es el lugar del control en la vida de los organismos? Nuestras intuiciones son un buen punto de partida: un acontecimiento es incontrolable cuando no podemos hacer nada para cambiarlo, cuando hagamos lo que hagamos, siempre ocurrirá lo mismo (Seligman, 1981, p. 27).

La desesperanza aprendida arrastra tres tipos de déficits, a lo largo de la vida: debilita la motivación para iniciar respuestas, disminuye la motivación para responder; perturba la capacidad de aprender que responder es efectivo; y produce perturbaciones emocionales, en especial, depresión y ansiedad.

El guardia de Auschwitz y los mochileros del 11-M tienen en común con estos con las mentiras respecto a la guerra de Lrak, y se contraponen a quienes levan una actividad presidida por el principio misericordia, que tantas personas llevan a cabo en su vida cotidiana; no es que unas de ellas estén dominadas por creencias y otras no, sino que unas dejan tras de sí un rastro oscuro de injusticia, muerte y destrucción (están presididas por la negatividad, en palabras de Enrique Dussel), y otras, en contra, siembran la vida y se acogen al principio esperanza, a ese principio según el cual creemos que no todo está hecho, que hay un horizonte abierto, que estamos en camino y que lo mejor está todavía por llegar, según la propuesta de Bloch (2004, pp. 12-15).

Creencias que crean víctimas; creencias que van seguidas de comportamientos y acciones que llevan dentro de sí la señal del pecado (Ellacuría), orillan la conmiseración con quien sufre (Sobrino), expanden la negatividad y la muerte (Dussel) o atentan directa y llanamente contra el bienestar físico, social y psicológico de personas concretas, de acuerdo con la propuesta emanada y ampliamente trabajada en el contexto de la psicología: ese es nuestro marco de referencia, en este epígrafe. La clave la hemos ido vislumbrando, a lo largo de las primeras páginas de este artículo: hay estructuras sociales que conviven en aparente armonía con condiciones que impiden a amplias capas de la población satisfacer sus necesidades más elementales; estructuras que marcan el camino de la discriminación, que favorecen la exclusión y están atravesadas por relaciones de dominación. Lo peculiar de estas situaciones no es su existencia, la cual encontramos a cada vuelta de la esquina, sino que serían incapaces de sobrevivir con tanta solvencia de no haber estado y seguir estando apoyadas sobre un fondo ideológico (creencias y valores), que las hacen lógicas, comprensibles y justificables, por muy deletéreas que sean sus consecuencias. Hay estructuras sociales que llevan impresas dentro de sí la marca de la negatividad, y negatividad es negación de la vida, negatividad es dominación, exclusión, humillación, en razón del color de la piel, de la confesión religiosa, del sexo, de las preferencias sexuales, ataque y persecución, en razón de las ideas y las convicciones políticas, etc. Negatividad es, en palabras de Enrique Dussel (1998, p. 318), imposibilidad para la produc- 
ción, la reproducción y el desarrollo de la vida humana. Todas esas cosas que se expresan en el sufrimiento de las víctimas, en un sufrimiento que se considera necesario, inamovible, finito.

Las víctimas como consecuencia de la puesta en práctica de un determinado ámbito de creencias. La pregunta ahora es obligada: ¿cuál es el criterio de víctima? El pecado social, dice Ellacuría, desde la teologia; la desesperanza, "lo insostenible, lo insoportable, en todos los sentidos para las necesidades humanas" (Bloch, 2004, p. 27); la falta de misericordia, diría Jon Sobrino; la emancipación, decimos desde la ciencia social. Distintas denominaciones para hacer referencia a un fenómeno que la psicología ha estudiado con intensidad, en los últimos cuarenta años: el bienestar físico, social y psicológico. En fundamento sustantivo porque, como en algún otro momento hemos tenido oportunidad de recordar (Blanco, Rojas y de la Corte, 2000), si la emancipación se constituye en el hecho fundante de la ciencia social, el bienestar se erige, por su parte, en la razón de ser de la psicología como ciencia y como profesión, y para ello no hay más que acudir al Artículo 5 de nuestro código deontológico: "El ejercicio de la psicología se ordena a una finalidad humana y social, que puede expresarse en objetivos tales como el bienestar, la salud, la calidad de vida, la plenitud del desarrollo de las personas y de los grupos, en los distintos ámbitos de la vida individual y social". Y decimos, hay determinadas estructuras de valores y creencias que ponen seriamente en peligro esta finalidad. La ponen en sí mismas y por sí mismas, y con mucha más frecuencia lo hacen por interdicción de unos modelos de relación interpersonal, de relación económico-laboral, de relación socio-política, pautados e institucionalizados, que eso y no otra cosa viene a ser lo que llamamos estructura social.

La negatividad, el pecado y la impiedad con el sufrimiento de los otros, como antítesis del principio misericordia, como contrapunto del bienestar, han tenido un marco común: la pobreza y la injusticia, los pobres como producto de la codicia y de la injusticia, dice Jon Sobrino (2003), como producto de "salteadores de caminos que producen victimas" (Sobrino, 1992, p. 42); de estructuras sociales opresoras (el pecado social), dice Ellacuría (1991). Cuando Rut Veenhoven, un investigador holandés, en el campo del bienestar, intenta poner a prueba su modelo de los determinantes de la satisfacción con la vida (oportunidades vitales, curso de los acontecimientos, flujo de la experiencia y evaluación de la vida) subraya algunos de estos hechos. Cuatro al menos: la satisfacción con la vida es, por lo general, mayor en las naciones económicamente más prósperas; la satisfacción con la vida es también mayor en las naciones donde hay una mayor igualdad social, sencillamente porque "la desigualdad social conlleva un mayor riesgo de acontecimientos sociales adversos y es una fuente de frustración en sí misma"; la satisfacción con la vida es, asimismo, más pronunciada en naciones donde los derechos humanos y las libertades políticas son muy respetados, y, por último, lo mismo sucede en países que ofrecen un mayor acceso al conocimiento, medi- 
do por las tasas de alfabetización, escolarización y audiencia de los medios de comunicación (Veenhoven, 1994, p. 102).

Resultados muy parecidos obtuvo Ronald Inglehart, tomando como punto de partida un par de preguntas incluidas en el Eurobarómetro (200 mil entrevistas desde 1973): "¿en general se encuentra usted satisfecho con su vida en conjunto? ¿Diría usted que está muy satisfecho, bastante satisfecho o insatisfecho?". Las variaciones a estas preguntas tienen dos características dignas de mención: son muy estables, a lo largo de los años, y muestran unas diferencias claramente significativas entre los países. Este último aspecto es el que nos interesa. Aquí, Inglehart se muestra en la misma dirección que Vennhoven: hay que tener en cuenta las diferentes experiencias históricas de los distintos países; más en concreto, "creemos que una de las fuentes de variación cultural más importante es un determinado nivel de desarrollo económico. La seguridad económica tiende a favorecer la sensación de satisfacción vital que prevalece en una sociedad, dando lugar gradualmente al surgimiento de una norma cultural relativamente asentada" (Inglehart, 1991, p. 20). Dato concreto, la prosperidad está ligada a niveles de satisfacción vital, relativamente altos, en las veintidós naciones de las cuales se obtuvieron datos, a lo largo de los años ochenta.

Desde que en 1967 se iniciara en la psicología el estudio sistemático del bienestar, se han venido poniendo de manifiesto la existencia de indicadores que nos remiten de manera clara a los supuestos sobre los que estamos intentando trazar un perfil de las víctimas: el nivel de instrucción, los ingresos, el género, los eventos vitales, la raza, la libertad política, la igualdad social, los recursos de que uno disponga para el bienestar (políticos y económicos), la seguridad, el empleo y las condiciones de trabajo, la libertad para el bienestar. Todos ellos han sido amplia y sólidamente manejados por expertos, desde Rut Veenhoven hasta Amartya Sen, Premio Nóbel de Economía de 1998, pasando por Ed Diener, y dibujan un panorama que se acerca definitivamente al concepto de víctima, por cuanto señalan hasta qué punto determinadas condiciones externas al sujeto, pertenecientes al mundo económico y político, son capaces de amargarles la existencia.

De entre todas estas aportaciones, la que consideramos especialmente pertinente para el principio esperanza es el concepto de Amartya Sen de libertad para el bienestar. El modelo centrado en las capacidades nos remite a ese sujeto insolidario, a ese ego autónomo, que cree ilusamente en una singularidad ajena al acontecer social, a la interioridad individualista de un ser concluso y cerrado sobre sí mismo, al cual hemos visto atravesar el desierto de su insocialidad. Frente a las capacidades, que cada uno de nosotros tiene para la consecución del bienestar, Sen propone tomar en consideración la libertad de que dispongamos para lograrlo (la libertad para el bienestar) porque, en muchas ocasiones, las supuestas capacidades no hacen sino reflejar "la libertad de una persona para elegir entre diferentes formas de vida", a la vez que la libertad te concede la posibilidad de 
desarrollar la capacidad. Capacidad para la esperanza y liberad para poder lograrla, una libertad que tiene, sin duda, razones económicas pero que, muchas veces, nos remite al mundo de los valores: las creencias como un freno para el bienestar.

\section{Referencias bibliográficas}

Asch, S. (1962), Psicologia social. Buenos Aires, Eudeba.

Bar-Tal, D. (1996), "Las creencias grupales como expresión de la identidad social", en J. Morales, D. Paéz, J. C. Deschamps, y S. Worchel (Eds.), Identidad social. Aproximaciones psicosociales a los grupos y a las relaciones entre grupos (pp. 255-285), Valencia, Promolibro.

Batson, D. (1991), The Altruism Question: Toward a Social-psychological Answer, Hillsdale, N.J., LEA.

Blanco. A., Rojas, D. y de la Corte, L. (2000), "La psicologia y su compromiso con el bienestar humano", en J. M* Peiró y P. Valcárcel (Eds.), Psicología y sociedad, Valencia, Real Sociedad Económica de Amigos del Pals.

Bloch, E. (2004), El principio esperanza I, Madrid, Trotta.

Camon, F. (1996), Primo Levi en diálogo con Ferdinando Camon, Barcelona, Anaya \& Mario Muchnik.

Campbell, D. (1969), "Reforms as Experiments", American Psychologist. 24, 409-429.

Comte, A. (1841-1981), La fisica social, Madrid, Aguilar.

Del Águila, R. (2005), "Políticas perfectas: ideales, moralidad y juicio", en A. Blanco. R. del Águila y J. M. Sabucedo (Eds.), Madrid II-M. Un análisis del mal y sus consecuencias, Madrid, Trotta.

Durkheim, E. (1898), "Représentations indivuduelles et représentations collectives", Revue de Metaphysique et de Morale, 6, 273-302.

Durkheim, E. (1912-1993), Las formas elementales de la vida religiosa, Madrid, Alianza. Dussel, E. (1998), Etica de la liberación, Madrid, Trotta.

Easlea, B. (1977), La liberación social y los objetivos de la ciencia, Madrid, Siglo XXI.

Elias, N. (1990), La sociedad de los individuos, Barcelona, Península.

Ellacuría, I. (1991). "Historicidad de la salvación cristiana", en I. Ellacuría y J. Sobrino (Eds.), Mysterium Liberationis. Conceptos fundamentales de la seologia de la liberacion (pp. 323-372), San Salvador, UCA Editores.

Ellacuría, I. (2000), Escritos reológicos I, San Salvador, UCA Editores.

Festinger, L., Riecken, H. y Schachter, S. (1956), When Prophecy Fails, Minnesota, Universily of Minnesota Press.

Fishbein, M. y Azjen, I. (1975), Belief, Atuiude, Intention, and Behavior. An Introduction to Theory and Research, Reading, Mass. Addison-Wesley.

Giner, S. (1987), Historia del pensamiento social, Barcelona. Ariel.

Gutiérrez, G. (1975), Teología de la liberaciôn. Perspectivas, Salananca, Ediciones Sígueme.

Horkheimer, M. (1974), Teoría crifica, Buenos Aires, Amorrortu.

Inglehart, R. (1991), El cambio cultural en las sociedades industriales avanzadas, Madrid, Centro de Investigaciones Sociológicas.

Janoff-Bulman, R. (1992), Shattered Assumptions: Towards a New Psychology of Trau$m a$, Nueva York, Free Press. 
Küng, H. (2000), Una éfica mundial para la economia y la polfrica, México, F.C.E.

Lukes, S. (1984), Emile Durkheim. Su vida y su obra, Madrid, Centro de Investigaciones Sociológicas.

Martín-Baró, I. (1983), Acción e ideología. Psicología social desde Centroamérica I, San Salvador, UCA Editores.

Nisbet, R. (1969), Los orfgenes del pensamiento sociológico I, Buenos Aires, Amorrortu.

Rivière, A. (1991), Objetos con mente, Madrid, Alianza.

Seligman, A. (1981), Indefension, Madrid, Debate.

Sen. A. (1996). "Capacidad y bienestar", en M. Nussbaum y A. Sen (Eds.), La calidad de vida (pp. 54-83), México, F.C.E.

Sobrino, J. (1992), El principio misericordia, San Salvador, UCA Editores.

Sobrino, J. (2003), Terremoto, terrorismo, barbarie y utopia. El Salvador, Nueva York, Afganistán, San Salvador, UCA Editores.

Veenhoven, R. (1994), "El estudio de la satisfacción con la vida", Intervención Psicosocial, 3, 87-I16.

Villoro, L. (1998), Creer, saber, conocer, México, Siglo XXI.

Vygotski, L. (1987), Historia del desarrollo de las funciones psiquicas superiores, La Habana, Editorial Cientlfico Técnica.

Wiesel, E. (1996), Memorias. Todos los torrentes van a dar a la mar, Barcelona, Anaya \& Mario Muchnik. 